\title{
PERSEPSI ORANG TUA TERHADAP LEMBAGA PENDIDIKAN ANAK USIA DINI
}

\author{
${\text { Siti } \text { Aisyah }^{1} \text { \& Ignatia Imelda Fitriani }}^{1}$ \\ ${ }^{1} 1$ Program Studi PG PAUD FKIP Universitas Palangka Raya \\ Jl. H. Timang Komplek Kampus Tunjung Nyaho Palangka Raya \\ Email : ignatia.imelda@fkip.upr.ac.id
}

\begin{abstract}
ABSTRAK
Persepsi merupakan seluruh proses akal manusia mengenai suatu cara pandang dan pemahaman ataupun pemberian makna seseorang mengenai suatu objek yang ada di sekitar lingkungannya melalui pengamatan, pengetahuan dan pengalamannya. Penelitian ini bertujuan untuk menjelaskan bagaimana persepsi orang tua terhadap lembaga pendidikan anak usia dini.

Metode yang digunakan dalam penelitian ini adalah metode deskriptif kuantitatif. Sampel dalam penelitian ini adalah orangtua yang memiliki anak usia 1-5 tahun di Kecamatan Sebangau. Lokasi pengambilan data dilakukan di posyandu abadi dan posyandu kuntum mekar yang berada di kelurahan kereng bangkirai. Teknik pengumpulan data yang digunakan adalah angket.

Berdasarkan hasil analisis data penelitian diketahui bahwa persepsi orang tua terhadap lembaga pendidikan anak usia dini di kecamatan sebangau, dapat disimpulkan sebagi berikut: hasil perhitungan nilai keseluruhan persepsi orang tua sebesar 63,49\% yang dapat dikategorikan "Baik".
\end{abstract}

\section{Kata Kunci : Persepsi. Orang Tua, Lembaga PAUD}

\section{PENDAHULUAN}

Pendidikan merupakan hak dan kewajiban bagi setiap orang di dunia. Pengertian pendidikan menurut Undang-Undang Nomor 20 Tahun 2003 tentang Sistem Pendidikan Nasional. Pendidikan bukan mutlak tanggung jawab sekolah, tetapi pendidikan merupakan tanggung jawab pemerintah, masyarakat, dan keluarga terutama ibu yang paling dekat dan paling sering bersama anak-anak mereka dalam kesehariannya. Dalam rangka menggali potensi anak diperlukan peran aktif orang tua. Orang tua berperan sebagai teladan yang memahami perkembangan anak dan juga memberikan pengasuhan serta pendidikan. Orang tua harus memiliki seperangkat pengetahuan, sikap, dan 
keterampilan yang dibutuhkan dalam mendidik anak. Namun sayangnya tidak semua orang tua memiliki perangkat-perangkat yang dibutuhkan dalam mendidik anaknya.

Pada saat anak memasuki usia 2-4 tahun adalah masa anak sebelum memasuki sekolah TK, orang tua terutama ibu adalah orang yang paling dekat dengan anak dan paling tahu apa yang dibutuhkan oleh anaknya. Maka orang tua harus memikirkan lembaga pendidikan anak usia dini seperti apa yang dibutuhkan yang mampu membantu dan memfasilitasi tumbuh kembang anaknya. Oleh sebab itu pendidikan anak-anaknya harus diatur atau direncanakan sejak dini.

\section{Pengertian Persepsi}

Matsumoto (dalam Wulandari (2017:23) menyatakan bahwa persepsi adalah tentang memahami bagaimana kita menerima stimulus dari lingkungan dan bagaimana kita memproses stimulus tersebut. Persepsi biasanya mengacu pada stimulasi atau perangsangan nyata pada organ-organ indera tertentu seperti mata (sistem visual), telinga (sistem pendengaran atau auditori), hidung (sistem penciuman atau olfaktori), lidah (pengecapan atau rasa), dan kulit (sentuhan). Persepsi biasanya dimengerti sebagai bagaimana informasi yang berasal dari organ yang terstimulasi diproses, termasuk bagaimana informasi tersebut diseleksi, ditata, dan ditafsirkan. Jadi persepsi mengacu pada proses di mana informasi.

Kotler (dalam Danarjati 2013: 22) menyatakan bahwa "persepsi sebagai proses bagaimana seseorang menyeleksi, mengatur dan menginterpretasikan masukan-masukan informasi untuk menciptakan gambaran keseluruhan yang berarti”. Sedangkan Robbins dalam Wulandari (2017:23) menyatakan bahwa "persepsi dalam kaitannya dengan lingkungan, yaitu sebagai proses di mana individu - individu mengorganisasikan dan menafsirkan kesan indera mereka agar memberi makna kepada lingkungan mereka.” Robbins (dalam Indriyani 2015:23) mendeskripsikan bahwa persepsi merupakan kesan yang diperoleh oleh individu melalui panca indera kemudian dianalisis (diorganisisasi), diintepretasi dan kemudian dievaluasi, sehingga individu tersebut memperoleh makna.

\section{Faktor-faktor yang Berperan dalam Persepsi}

Thoha (dalam Danarjati 2013: 24) menyatakan bahwa persepsi pada umumnya terjadi karena dua faktor, yaitu faktor internal dan faktor eksternal. Faktor internal 
berasal dari dalam diri individu, misalnya sikap, kebiasaan, dan kemauan. Sedangkan faktor eksternal adalah faktor - faktor yang berasal dari luar individu yang meliputi stimulus itu sendiri, baik sosial maupun fisik.

Oskamp (dalam Danarjati 2013:25) menyatakan bahwa, persepsi individu dipengaruhi oleh faktor fungsional dan struktural. Faktor fungsional adalah faktorfaktor yang bersifat personal. Misalnya kebutuhan individu, usia, pengalaman masa lalu, kepribadian, jenis kelamin, dan hal- hal yang bersifat subjektif. Faktor struktural adalah faktor di luar individu, misalnya lingkungan, budaya, dan norma sosial sangat berpengaruh terhadap seseorang dalam mempersepsikan sesuatu.

\section{Aspek-aspek dalam persepsi}

Sebagaimana pendapat Thoha di atas disebutkan bahwa salah satu faktor yang mempengaruhi persepsi adalah sikapnya. Pada hakekatnya sikap adalah merupakan suatu interelasi dari berbagai komponen yang menurut Allport (dalam Danarjati, 2013) terbagi menjadi tiga yaitu:

1. Komponen kognitif yang tersusun atas dasar pengetahuan atau informasi yang dimiliki seseorang tentang obyek sikapnya. Dari pengetahuan ini kemudian akan terbentuk suatu keyakinan tertentu tentang obyek sikap tersebut.

2. Komponen afektif yang berhubungan dengan rasa senang dan tidak senang. Jadi sifatnya evaluatif yang berhubungan erat dengan nilai - nilai kebudayaan atau sistem nilai yang dimilikinya.

3. Komponen Konatif merupakan kesiapan seseorang untuk bertingkah laku yang berhubungan dengan obyek sikapnya.

\section{Orang Tua}

Ahmad (1995:7-8) menyatakan bahwa orang tua adalah orang yang menjadi panutan anaknya. Setiap anak mula-mula mengagumi kedua orang tuanya. Semua tingkah laku orang tuanya ditiru oleh anak itu. Orang tua adalah pendidik utama dan pertama dalam hal penanaman keimanan bagi anaknya. Disebut pendidik utama karena besar sekali pengaruhnya. Disebut pendidik pertama, karena merekalah yang pertama mendidik anaknya. 


\section{Lembaga Pendidikan Anak Usia Dini (PAUD)}

Merujuk pada UU No. 20 Tahun 2003 tentang Sisitem Pendidikan Nasional disebutkan bahwa pendidikan adalah usaha sadar dan terencana untuk mewujudkan suasana belajar dan proses pembelajaran agar peserta didik secara aktif dapat mengembangkan potensi dirinya untuk memiliki kekuatan spiritual keagamaan, penegndalian diri, kepribadian, kecerdasan, akhlak mulia serta keterampilan yang diperlukan dirinya, masyarakat, bangsa, dan Negara.

Ki Hajar Dewantara (dalam Yus Anita) menyatakan bahwa, anak-anak ialah makhluk hidup yang memiliki kodratnya masing-masing. Kaum pendidik hanya membantu menuntun kodratnya ini. Kodrat dan lingkungan merupakan konvergensi yang saling berkaitan dan memengaruhi satu sama lain. Pandangan Ki Hajar tentang pendidikan adalah ing ngarso sungtulodo, ing madya mangu karso, tut wuri handayani. Sistem yang di pakai ialah sistem "among". Sistem ini mendidika anak menjadi manusia yang merdeka batinnya, pikirannya, dan tenaganya, serta dapat mencari pengetahuan sendiri. Filosofi yang dianut Ki Hajar Dewantara adalah asah, asih, dan asuh.

\section{METODE PENELITIAN}

Penelitian ini dilaksanakan di kecamatan Sebangau Kota Palangka Raya tepatnya di Posyandu Abadi dan Posyandu Kuntum Mekar yang berlokasi di Kelurahan Kereng Bangkirai yang dilaksanakan pada bulan Februari tahun 2019 dengan menggunakan pendekatan kusntitstif deskriptif. Pengumpulan data dilakukan menggunakan tehnik penyebaran kuesioner pada orangtua yang memiliki anak usia 2-4 tahun. Kuesioner disusun peneliti berdasarkan kisi-kisi indikator persepsi terhadap layanan Lembaga Pendidikan Anak Usia Dini yang telah diuji validitas dan dinyatakan valid. Data yang diperoleh kemudian dianalisis menggunakan tehnik prosentase.

\section{HASIL DAN PEMBAHASAN}

\section{Hasil Penelitian}

Uji instrumen penelitian ini dilakukan kepada 35 orang tua, dengan skala penelitian variabel (persepsi orang tua) dengan kriteria t tabel 0,344, diketahui bahwa jumlah item yang valid yaitu berjumlah 18 item dan yang gugur atau tidak valid berjumlah 7 item. Sedangkan uji reliabilitas yang diterapkan terhadap instrumen 
menunjukan nilai 0,826 dan dinyatakan reliable. Profil responden dalam penelitian ini disajikan sebagai berikut :

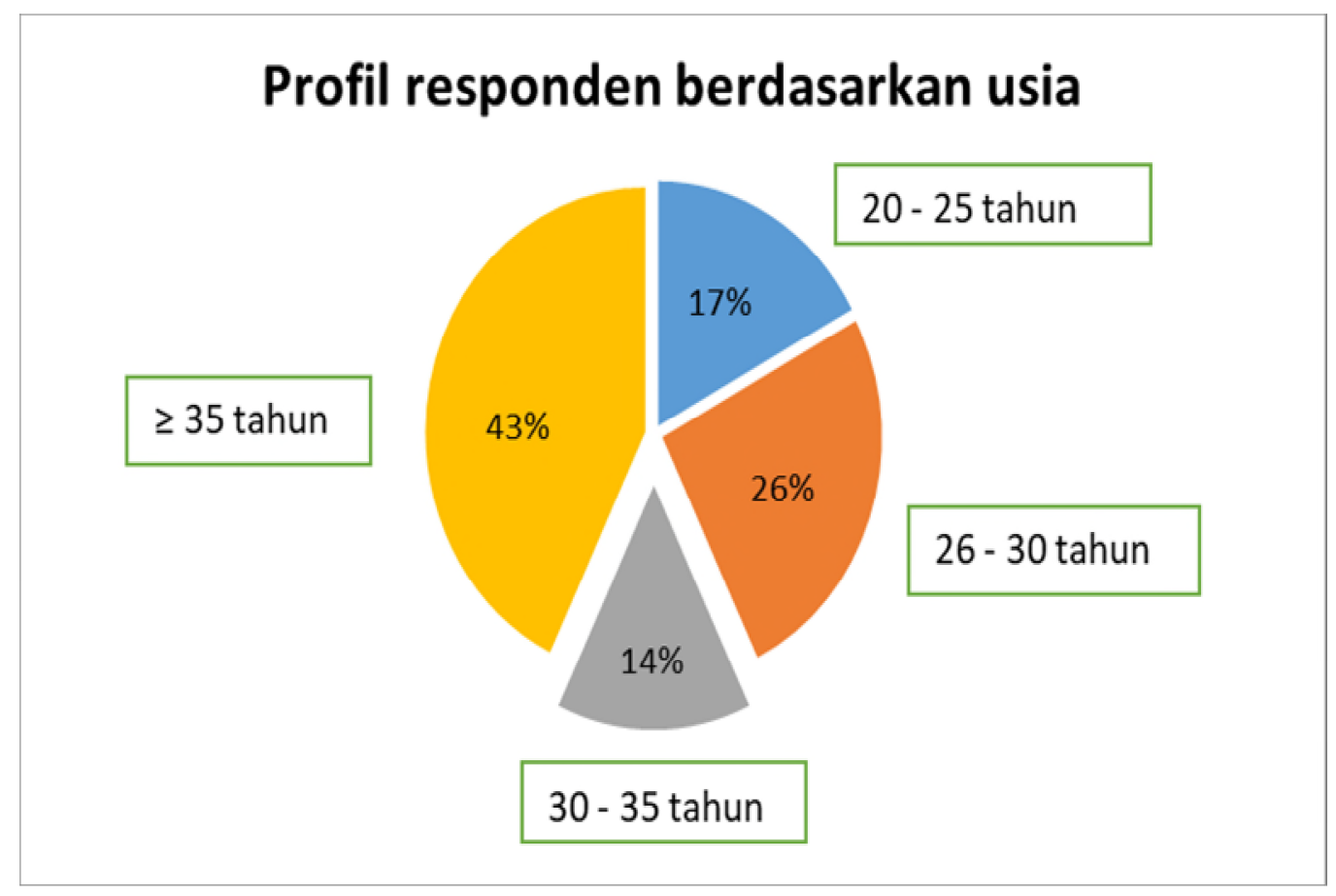

Gambar 1. Profil responden berdasarkan usia

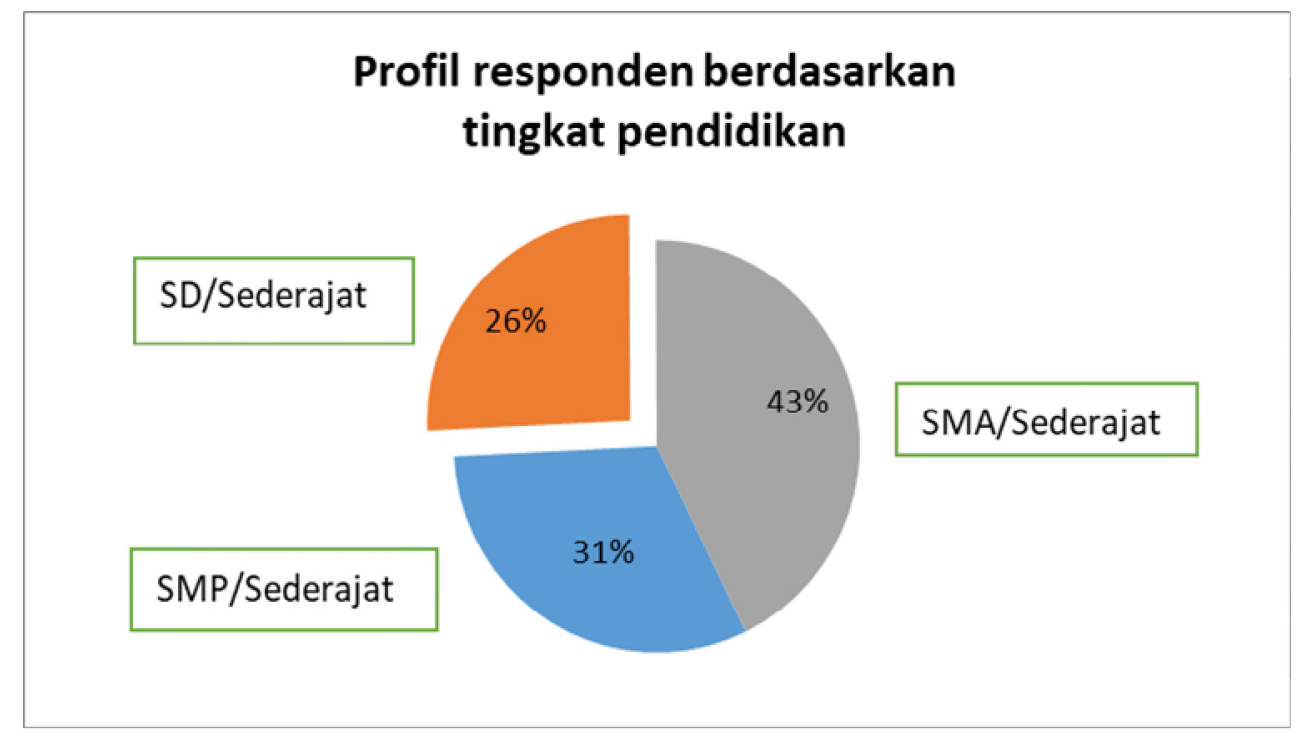

Gambar 2. Profil responden berdasarkan tingkat pendidikan 


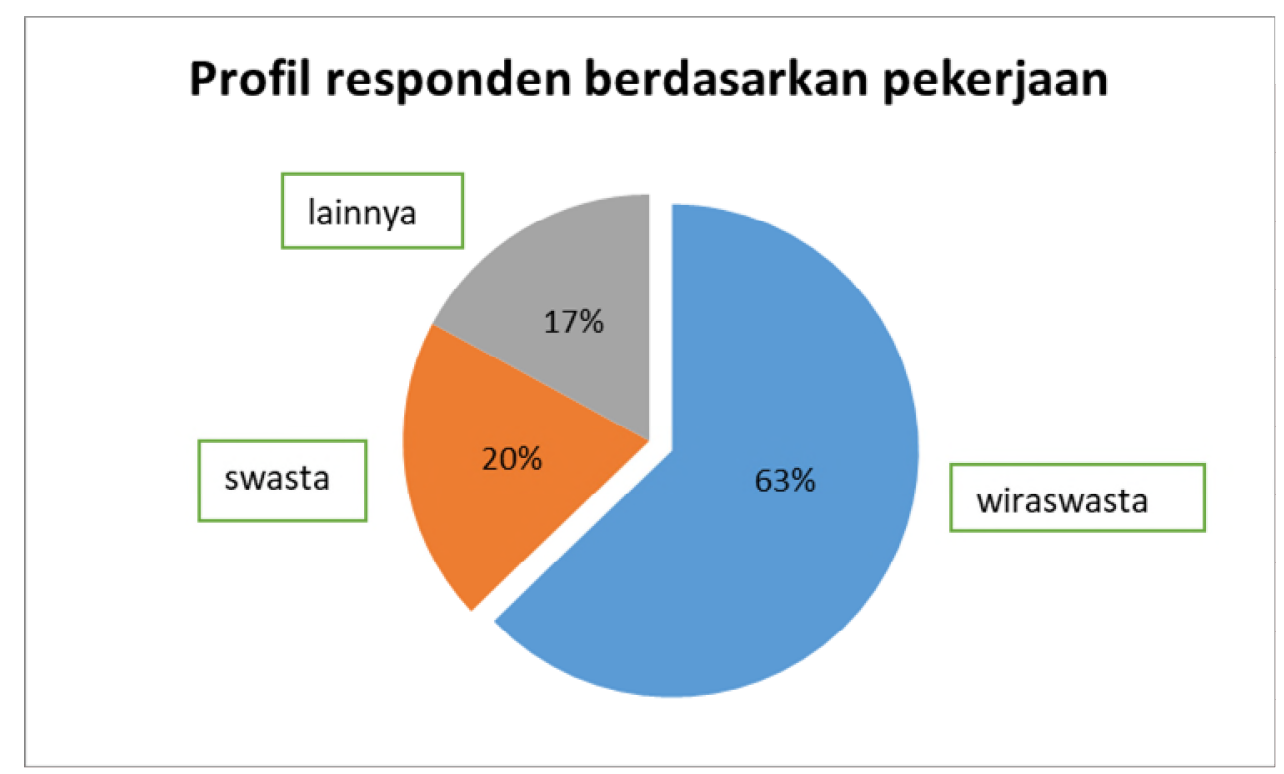

Gambar 3. Profil responden berdasarkan pekerjaan

Berdasarkan data dan hasil penelitian telah diperoleh skor keseluruhan dari angket yang telah di jawab oleh orang tua memperoleh presentase sebesar $63,49 \%$. Sehingga Persepsi Orang Tua Terhadap Lembaga Pendidikan Anak Usia Dini di Kecamatan Sebangau tahun 2019 dapat di golongkan dalam kategori "Baik".

Dari hasil penelitian yang telah dilakukan di Kecamatan Sebangau kepada orang tua melalui metode penyebaran angket, maka penulis akan menganalisis data untuk menjawab rumusan masalah dari penelitian ini. hasil keseluruhan yang diperoleh peneliti mengenai persepsi orang tua terhadap lembaga pendidikan anak usia dini di kecamatan sebangau tahun 2019 memperoleh persentase sebesar 63,49\% dengan kategori "Baik". Dengan begitu peneliti dapat menegetahui bahwa menurut orang tua pendidikan itu sangat penting dan dibutuhkan bagi anak karena dengan adanya lembaga PAUD dapat membantu meningkatkan perkembangan anak dan karena beberapa perkembangan tidak bisa hanya di dapatkan dalam keluarga, misalnya perkembangan sosial dan emosional. Selain itu dengan adanya lembaga PAUD orang tua merasa terbantu karena lembaga PAUD memiliki fasilitas yang di butuhkan dalam tumbuh kembang anak yang tidak dimiliki oleh orang tua di rumah dan dapat memberikan pembelajaran ketika orang tua bekerja/sibuk. Kemudian orang tua merasa puas dengan 
fasilitas lembaga PAUD yang berada di lingkungannya dan sudah merencanakan akan menyekolahkan anaknya sejak awal masa sekolah, dan akan turut serta membangun lembaga PAUD yang berada di lingkungannya. Oleh sebab itu persepsi orang tua terhadap lembaga pendidikan anak usia dini di kecamatan sebangau dapat dikatakan "Baik".

\section{KESIMPULAN}

Dari hasil penelitian tersebut orang tua berpandangan bahwa adanya lembaga pendidikan anak usia dini memang sangat dibutuhkan, hal ini di buktikan dengan hasil skor penelitian yang diperoleh dari perhitungan keseluruhan adalah sebesar 63,49\%. Dengan persentase tersebut persepsi orang tua Terhadap Lembaga Pendidikan Anak Usia Dini di Kecamatan Sebangau Tahun 2019 dapat dikategorikan "Baik" karena orang tua mempunyai persepsi yang positif terhadap lembaga PAUD 


\section{DAFTAR PUSTAKA}

Arikunto, Suharsini. 2013. Prosedur Penelitian Suatu Pendekatan Praktik. Jakarta: Rineka Cipta

Asfarina, Hamimi. Made Widnya, \& Herlina. 2014. Persepsi Orang Tua Terhadap Pendidikan Anak Usia Dini di PAUD Ceria Desa Sesela Kabupaten Lombok Barat. Lombok: FIP IKIP Mataram.

Hasbullah. 2015. Dasar-dasar Ilmu Pendidikan. Jakarta. PT RajaGrafindo Persada.

Hikmat. 2009. Manajemen Pendidikan. Bandung. CV Pustaka Setia.

Indriyani, Sumaryono, dan Deviani Ismandari. 2015. Persepsi Mahasiswa Kependidikan Fakultas Ekonomi Universitas Negeri Yogyakarta Terhadap Pendidikan Profesi Guru (PPG). Yogyakarta: Universitas Negeri Yogyakarta

Irwanto. 2002. Psikologi Umum Buku Panduan Mahasiswa. Jakarta: Prenhallindo Priyatno, Duwi. 2014. SPSS 22: Pengolahan Data Terpraktis. Yogyakarta: Andi Offset Rakhmat, Jalaluddin. 2013. Psikologi Komunikasi. Bandung: Remaja Rosdakarya Riduwan. 2014. Pengantar Statistika. Bandung: Alfabeta

Sarwono, Sarlito Wirawan. 2002. Psikologi Sosial Individu dan Teori-Teori Psikologi Sosial. Jakarta: Balai Pustaka

Sion, Holten, Dkk. 2017. Pedoman Penulisan Skripsi. Palangka Raya: UPR

Siregar, Nina Siti Salmaniah. 2013. Persepsi Orang Tua terhadap Pentingnya Pendidikan bagi Anak. Medan: Universitas Medan Area.

Sudijono, Anas. 2015. Pengantar Statistik Pendidikan. Jakarta. RajaGrafindo Persada Sugiyono. 2014. Metode Penelitian Manajemen. Bandung: Alfabeta

Sugiyono. 2017. Metode Penelitian Pendidikan Pendekatan Kuantitatif, Kualitatif, dan $R \& D$. Bandung: Alfabeta

Suyadi. 2010. Psikologi Belajar PAUD. Yogyakarta: Pedagogia.

Tim Dosen. 2009. Manajemen Pendidikan. Bandung. Penerbit Alfabeta.

Tim Penyusun. 2007. Kamus Besar Bahasa Indonesia (Edisi Ketiga). Jakarta : Balai Pustaka

Walgito, Bimo. 2003. Psikologi Sosial (Suatu Pengantar). Yogyakarta: Penerbit Andi Wiyani, Novan Ardy. 2016. Konsep Dasar PAUD. Yogyakarta: Gava Media

Wulandari, Ayu. 2017. Pengaruh Persepsi Orang Tua Tentang Pendidikan Formal Dan Lingkungan Tempat Tinggal Terhadap Pekerja Anak Di Kelurahan Pidada Kecamatan Panjang Kota Bandar Lampung. Bandar Lampung: Universitas Lampung

Yus, Anita. 2014. Model Pendidikan Anak Usia Dini. Jakarta: Kencana 